\title{
IUID Method-Mix: Towards a Systematic Approach for Intercultural User Interface Design (IUID)
}

\author{
Rüdiger Heimgärtner \\ Intercultural User Interface Consulting (IUIC), Undorf, Germany \\ Email: ruediger.heimgaertner@iuic.de
}

How to cite this paper: Heimgärtner, R. (2019) IUID Method-Mix: Towards a Systematic Approach for Intercultural User Interface Design (IUID). Journal of Computer and Communications, 7, 162-194. https://doi.org/10.4236/jcc.2019.77015

Received: April 8, 2019

Accepted: July 15, 2019

Published: July 18, 2019

Copyright ( 2019 by author(s) and Scientific Research Publishing Inc. This work is licensed under the Creative Commons Attribution International License (CC BY 4.0).

http://creativecommons.org/licenses/by/4.0/

\section{Open Access}

\begin{abstract}
A method-mix for intercultural user interface design (IUID) is explained and exemplified by application examples based on a hybrid approach covering cultural contexts in human-computer interaction (HCI) design using a model of culturally influenced HCI. Cultural influence on HCI is described using cultural variables for user interface design. Assumptions and empirical results regarding the influence of culture on HCI, considering the path of the information processing and the interaction style between Chinese and German users are explained based on cultural models. Subsequent indicators represent the relationship between culture and HCI (culturally imprinted by the user). Correlations adopted theoretically between cultural dimensions and variables for HCI design were investigated. These correlations represent relevant constituents of a model for culturally influenced HCI. Considerations applying this model and evidence for the proper application of the IUID method-mix are presented elucidating why and how cultural aspects play a role in $\mathrm{HCI}$ design and usability/UX engineering. The IUID method-mix serves to inspire $\mathrm{HCI}$ engineers in the requirement analysis phase as well as HCI designers in the design phase. The readers are thereby sensitized to the challenges of intercultural usability/UX engineering and intercultural HCI design and will be equipped with methodological knowledge relevant to the derivation of design recommendations for user interface design for and in their desired cultural contexts. Finally, implications for practitioners are shown, including HCI style scores and practical design recommendations, to prognosticate the effort and the expenditures for considering the cultural context in IUID.
\end{abstract}

\section{Keywords}

Culture, Human Factors, UX, Usability Engineering, Intercultural User Interface Design, Method Mix, HCI Dimensions, HCI, HMI, Cross-Cultural, Design, 
Intercultural, Culture-Centered, Methods, Tools, Standards, State of Research, Cultural Differences, Communication, Understanding, Empathy, Intercultural Communication, Intercultural HCI Design, Process, Cycle, IUID

\section{Introduction and Related Work}

Intercultural user interface design (IUID) is a prerequisite for improving the intercultural usability of software, which in turn is a prerequisite for global sales opportunities [1]. Using methods of intercultural usability engineering (IUE), further design guidelines can be iteratively derived from the results of the tests and the feedback of potential users from all over the world for IUID [2]. Hence, the perception and consideration of the customs and requirements of other cultures by the developers of intercultural user interfaces are one of the main tasks within IUID [3]. There are several papers in the literature review concerning the usage of information systems in their cultural context. Two of the first books regarding internationalization of Human-Computer Interaction (HCI) are "Designing User Interfaces for International Use" by [4] and "International User Interfaces" by [5]. Another very good introduction to the study of cross-cultural of HCI is [6], which reviewed the research methodology, the technology transfer and the diffusion of innovation to shed light on the cross-cultural study of human-computer interaction. Another overview of culture and its effects on HCI is given by [7]. There is also activity investigating the trends in intercultural HCI (cf. [8]). [9] did a review of culture in information systems research to postulate a shift to a theory of information technology for cultural conflict. [10] illuminated the relationship between culture and computers by a review of the concept of culture and the implications for intercultural collaborative online learning. [11] provided an overview of a decade of journal publications about culture and HCI. [12] provided an overview of the state of research in IUID. There are several groups of IUID researchers concentrating on special topics. For instance, [13] developed a semiotic based approach for IUID. [14] investigates cultural centered design in general. [2] [15] and [16] work in the area of IUID. [17] investigated indigenous HCI and [18] intercultural usability testing. Before 1990, there were almost no publications available that would relate the concepts "culture" and "HCI" one another. Pioneers working between 1990-1999 and from 2005-2010 evaluated the new field systematically. Since 2010 strongly driving research in this field has risen. However, even if since 2000 and especially since 2010, the research and literature accounting for cultural contexts in human-computer interaction (HCI) design have quickly grown, there are few studies bridging the gap between researching models and methods for IUID in order to have practical value for user interface (UI) designers right there where culture in $\mathrm{HCI}$ is often still considered a matter of internationalization or localization [19]. However, there are some cornerstones in developing systematic IUID approaches: For example, [18] suggested a theory for usability testing in 
cultural contexts, [20]-[25] proposed reflections towards a model for intercultural HCI design, [13] purported a semiotic based way to derive design recommendations for information systems. Nevertheless, there is still a remarkable knowledge gap regarding the relationship between culture and $\mathrm{HCI}$ in order to derive usable design recommendation for practitioners.

\section{IUID Method-Mix}

Based on feedback from tutorials and workshops on IUID (M \& C 2010, Interact 2011, SouthCHI 2013, HCII 2014, IHCI 2015, M \& C 2017, M \& C 2018) and the summary of the state of research on IUID in [20] [12] and [26], the author reviewed the synopsis of well documented IUID methods in scientific literature to form a hybrid approach integrating several IUID concepts and methods into one IUID method mix. Today, strategies for IUID address at least one of the following concepts in the wide context contributing to good intercultural usability engineering (cf. [27]) and intercultural user interface design [12]:

- User interface characteristics (cf. [28]).

- Method of culture oriented HCI design [2].

- Intercultural variables (cf. [2]).

- HCI dimensions (cf. [29]).

These concepts are used to support the design process which finally should lead to good user interfaces of high usability providing excellent user experience. However, the successful application of these approaches strongly depends on successful intercultural communication which again depends on the personal ability to mutually understand the web of belief of the others using empathic capabilities [30]. In the following, the elements of this process are described in detail to bridge the divergence represented by the gap in the knowledge of the differences in intercultural HCI design using converging methods and approaches.

\subsection{Cultural Dimensions}

The position that is taken in this article is that culture is a set of facts (structural conditions) representing an orientation system [31] established by collective programming of the mind [32] within a group of individuals. The larger the set of facts shared by the group members, the stronger the culture and the stronger the members' sense of belonging to the group. Therefore, cultures are referred to as every group of people with similar values, norms, and rules leading to similar habits and behavior. The orientation system of this group serves to identify the members with the group themselves (and, hence, the culture in this group) and to separate themselves from other groups representing another culture. For example, the analysis of the cultural shaping of people from Western and Asian regions reveals a large cultural distance ([33], pp. 16 seq.). The distance felt thereby between peoples and culture arises from the different expressions of the structural features of a specific culture or cultural group. The probability of misunderstand- 
ing is proportional to the size of the cultural distance ([34], pp. 33-34).

Cultural differences and distances can be described and categorized with the help of cultural models. Cultural models describe the cultural distance, that is, the differences between cultures and allow the comparison of them with each other [35]). One of the best-known cultural models is the iceberg model of culture [5]: Only a few of the attributes of a culture are visible and conscious. The rest is invisible and unconscious and, hence, difficult to investigate. Cultural models help to overcome this methodological gap using cultural standards and dimensions to look beneath the water surface, that is, to probe the unconscious areas of culture.

The organizational psychologist Alexander Thomas established the concept of "cultural standards," which expresses the normal, typical, and valid attributes for most of the members of a certain culture regarding the kinds of perception, thoughts, judgments, and actions ([31], p. 112). Cultural standards serve as an orientation system for the members of a group and regulate action. The individual grows into its culture by taking over and internalizing these cultural standards. This process encompasses learning basic human abilities in the social arena, control of one's own behavior and emotions, the satisfaction of basic needs, worldview, verbal and nonverbal communication, and expectations of others as well as the understanding of one's role and scales for judgment.

Another key concept for describing a cultural system is that of "cultural dimension," which can serve as a basis for the identification of cultural standards ([36], p. 38). According to Hofstede, cultural dimensions are quantitative models to describe the behavior of the members of different cultures allowing the analysis and comparison of the characteristics of different groups quantitatively [32] because the cultural imprint of cultural groups can be measured using quantitative questionnaires [37]. They represent an aspect of a culture, which is measurable in relation to other cultures. Hence, cultural dimensions can be used to classify kinds of behavior between cultures. Cultural dimensions are indicators showing tendencies in the interaction and communication behavior of members of cultures. Hofstede applied cultural dimensions to nations. Their specific values represent the character of the national culture (when applied at least to groups of more than 20 members; [37], the more members of a nation are asked, the more representative the character of the national culture), which is relatively stable also within countries (cf. [38]). The extent of the membership in a dimension is indicated numerically with an index (PDI, IDV, MAS, UAI, and LTO). Power distance (PDI): PDI represents the acceptance of social inequality and the relationship to authority, that is, the extent up to which the less powerful members of institutions or organizations of a country expect that power is distributed dissimilarly ([39], p. 42). Individualism versus collectivism (IDV): This dimension describes the attitude of an individual toward living in groups. A high individualism index indicates societies in which the relationships are loose between the individuals: One expects everybody to take care of himself and his immediate 
family. A low individualism index indicates collectivistic societies, in which persons are integrated into collective groups from birth, which protects them for life and expects unconditional loyalty from them ([39], p. 67). Femininity versus masculinity (MAS): This dimension represents the social implications of gender. A society demonstrates how clearly the roles of sexes are delimited from each other. Masculinity means being forceful and strong as well as having a materialistic orientation. Femininity means being modest, being more sensitive, and attaching importance to quality of life. Higher femininity indicates a society in which the roles of the sexes overlap: Both women and men should be modest and sensitive and put value on quality of life ([39], p. 101). Uncertainty avoidance (UAI): This index represents the degree to which members of a culture feel threatened by uncertain or unknown situations. It is also an indicator for expressing the way to deal with uncertainty regarding controlling emotions and aggression ([39], p. 133). Long-term versus short-term orientation (LTO): Long-term oriented cultures stand for staying power, relation resistance, and the retention of these relations to foster virtues toward future rewards, perseverance and thrift ([39], p. 401). Short-term oriented societies show a high personal stability, keeping dignity (preservation of face), respect for tradition, and fostering virtues related to past and present ([39], p. 403). For example, in China, there is high "power distance" in contrast to Germany. Power distance represents a quantitatively measurable aspect of a national culture, which quantifies the degree to which less powerful members of institutions and organizations in a country expect and accept disparate distribution of power ([39], p. 42). The PDI ranges from zero to about 100 . Hofstede determined that the power distance in China is high $(\mathrm{PDI}=80)$ compared to Germany $(\mathrm{PDI}=35)$. This may be relevant in intercultural HCI design, with respect to accepting help or commands (given by the system) by the user according to his acceptance of external power.

In contrast, Hall based his cultural models such as context information, message speed, and mono-chronic or poly-chronic time orientation on qualitative interviews and field studies [40]. There are many more founders of cultural dimensions, for example, [41] [42] [43] [44] and [45]. The idiosyncratic values of these dimensions have been determined for many nations by their authors (cf. [33], or [46]).

Cultural dimensions are too rough for intercultural user interface design. For this reason, additional inter cultural variables are necessary which-in relation to the user interface design-divide the cultural aspects into smaller units (cf. [2] [47]). These cultural aspects and their manifestations can be empirically determined using qualitative and quantitative methods. Although cultures are constantly changing (cf. [48]), for a product life cycle of a few years at least trends can be determined, and for special cases of an application even selective parameters can be determined which serve the intercultural user interface design.

\subsection{Intercultural Variables}

According to [49]: 93-96, intercultural variables describe the differences in HCI 
design regarding the preferences of the users of different cultures. "Intercultural" variables represent knowledge that can be obtained only by observing at least two cultures and their differences, i.e. doing intercultural research (cf. [50]) to obtain relevant knowledge for internationalization of software and system platforms. Their values represent culture-dependent variations that occur at all levels of HCI localization (surface, functionality and interaction) (cf. [2]) and can be used for intercultural user interface design. Intercultural variables describe the differences in HCI design with respect to the preferences of users from different cultures (cf. Table 1).

Direct intercultural variables are most important because they have a direct and essential influence on the HCI design. "Visible" intercultural variables (VIVs) (above the "water surface" of the iceberg-metaphor) are immediately perceptible at a certain time (font, color, window size, navigation, etc.). In contrast, "invisible" (or "hidden") intercultural variables (NVIVs) (below the "water surface") are only recognizable over a certain period (such as interaction speed, information display duration, dialogue display frequency, use of the navigation bar, etc.). The localization of hidden intercultural variables is difficult to realize because the contextual relation to the cultural background as well as to the product is very strong for interaction and dialogue design. However, this culturally distinct context and consequently its cultural dependency is precisely the reason (cf. iceberg metaphor), why these patterns and non-visible intercultural variables are so important for information architecture as well as for interaction design and, hence, for the resulting dialogues of a product ([49], p. 98). And therefore, intercultural variables and their values representing knowledge for a specific culture (relevant for system and software localization) need high research priority (e.g. using special tools as suggested by [51]).

Table 1. Intercultural variables according to [49]: 97 et. seqq. (estimated values regarding the difficulty to recognize the variables are added by the author).

\begin{tabular}{ccccc}
\hline Intercultural variable & $\begin{array}{c}\text { Level of } \\
\text { localization }\end{array}$ & $\begin{array}{c}\text { Relation to } \\
\text { HCI design }\end{array}$ & $\begin{array}{c}\text { Perceivability } \\
\text { of the variables }\end{array}$ & $\begin{array}{c}\text { Estimated } \\
\text { difficulty to } \\
\text { recognize } \\
\text { [0 (easy) - } \\
10 \text { (difficult) }\end{array}$ \\
\hline Dialog design & Interaction & Direct & $\begin{array}{c}\text { Hidden/Over long time and } \\
\text { deep analysis }\end{array}$ & 10 \\
Interaction design & Interaction & Direct & $\begin{array}{c}\text { Hidden/Over long time and } \\
\text { deep analysis }\end{array}$ & 9 \\
System functionality & Function & Indirect & Visible/Immediately & 8 \\
Service (Maintenance) & Function & Indirect & Visible/Immediately & 7 \\
Technical documentation & Function & Indirect & Visible/Immediately & 6 \\
Information presentation & Surface & Direct & Visible/Immediately & 4 \\
Language & Surface & Direct & Visible/Immediately & 2 \\
General system design & Surface & Indirect & Visible/Immediately & 0 \\
\hline
\end{tabular}




\subsection{Method of Culture-Oriented Design}

[49]: 108 used inter cultural variables to develop an approach for the design of intercultural human-machine systems using the "method of culture-oriented design" (MCD), which integrates the factors of new concepts of culture-oriented HCI design and the knowledge of cultural differences into existing concepts of HCI design (cf. Figure 1).

Knowledge about cultural differences is resultantly integrated into existing methods to include intercultural aspects in human-machine interaction. Relevant cultural variables for intercultural HCI design must be determined analytically based on literature research and empirical requirement studies.

\subsection{User Interface Characteristics}

[47] developed characteristic factors for user interfaces that can influence user interface design to make cultural dimensions available for user interface design: The user interface characteristics "metaphor", "mental model", "navigation", "interaction" and "presentation" are connected to the five cultural dimensions of Hofstede. For instance, according to [28] and [52], Chinese people (and hence users) are rather relationship and family oriented based on traditional powerful social hierarchical structures. In contrast, German users are described as event oriented regarding acts, tools, work, jobs and competition. Some tendencies regarding cultural differences can be used for intercultural user interface design and further reflections and research. User interface characteristics can be used in conjunction with empirical surveys on their characteristics for the corresponding cultural target context to derive recommendations for the development of intercultural user interfaces. Table 2 shows a summary of general recommendations for intercultural user interface design based on [53].

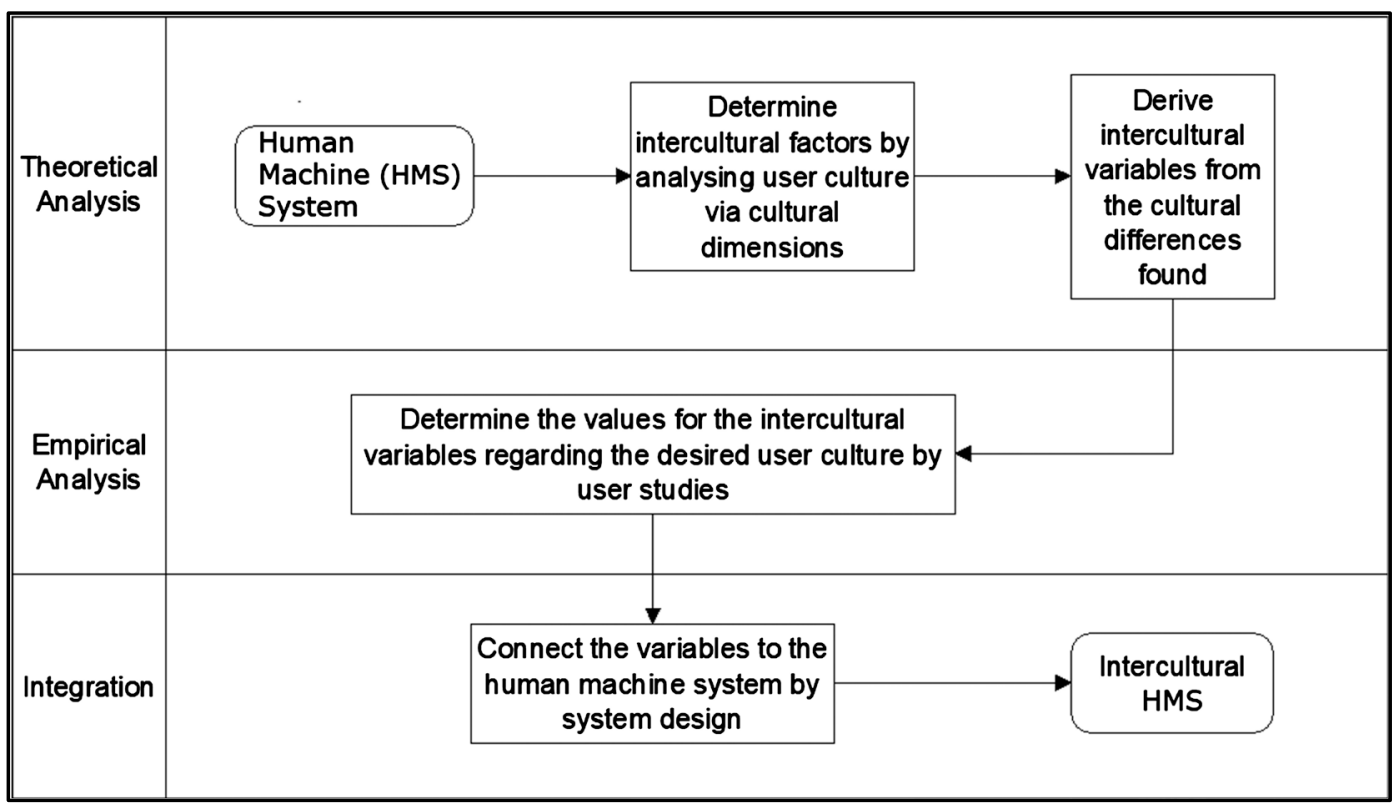

Figure 1. Simplified version of the Method of Culture-oriented Design (MCD) (Source: [20]: 66). 


\subsection{HCI Dimensions}

Based on the work of [32] [40], and [54], [55] introduced the concept of HCI dimensions to support the determination of the relationship between culture and HCI (cf. [20] [21]).

HCI dimensions (HCIDs) represent the characteristics of HCI by describing the HCI style of the user, i.e. the path of information processing and the interaction style exhibited by the user based on the concepts of "information" and "interaction" according to HCI dialogs (cf. [56]) that are characterized by transmitting pieces of information during user system interaction derived from the basic physical dimensions of space and time as well as from their sub-dimensions: frequency, speed, duration, density, and order (cf. Table 3).

Frequency, density, order and structure are concerned particularly during information processing; frequency and speed are concerned during interaction behavior. HCI dimensions can be regarded as the main factors relevant for HCI design, because they denote the basic classes for variables useful in HCI design.

The view of space, time and mental aspects is strongly culture dependent (cf. [57]). HCI is, therefore, also culture dependent, because HCI dialogs, interaction, information presentation and with that $\mathrm{HCI}$ generally are strongly linked with time (interaction, communication) and space (layout, structure) as well as

Table 2. Summary of recommendations for intercultural HCI design according to the user interface characteristics regarding China and Germany (summarized by the author in accordance to table 6-3 in [53]: 138 as well as to [53]: 305-317).

\begin{tabular}{lll}
\hline $\begin{array}{l}\text { User Interface } \\
\text { Characteristics }\end{array}$ & China & Germany \\
\hline Metaphor & Use clear hierarchy and representation instead of abstraction & Use representation instead of abstraction \\
Mental model & $\begin{array}{l}\text { Use many references without any sequence of relevance, simple } \\
\text { mental models, clear articulation, limited choice and binary logic }\end{array}$ & $\begin{array}{l}\text { Use few references with sequence of relevance and } \\
\text { fuzzic }\end{array}$ \\
Navigation & Use limited and predefined choice and navigation & Use open access and arbitrary choice and unique \\
Interaction & Use personalized but team-oriented systems giving direct error & navigation \\
messages, guided help and providing face-to-face interaction & $\begin{array}{l}\text { open and flexible interaction with the system (e.g., full } \\
\text { text search) }\end{array}$ \\
Presentation & $\begin{array}{l}\text { Use formal speech providing high contextual relationship-oriented } \\
\text { information as well as feminine colors }\end{array}$ & $\begin{array}{l}\text { Use informal speech providing low contextual } \\
\text { task-oriented information as well as masculine colors }\end{array}$ \\
\hline
\end{tabular}

Table 3. HCI Dimensions according to [20].

\begin{tabular}{lll}
\hline $\begin{array}{l}\text { Derived Physical Sub-Dimensions } \\
\text { [Basic Physical Dimension] }\end{array}$ & Information Related HCI Dimension & Interaction Related HCI Dimension \\
\hline Frequency [Time] & Information frequency & Interaction frequency \\
Speed [Time] & Information speed & Interaction speed \\
Sequentiality/Priority/Order [Time and Space] & Information order/Information parallelism & Interaction order/Interaction parallelism \\
$\begin{array}{l}\text { Density/Quantity [Time and Space]/ } \\
\text { Context [Time and Space] }\end{array}$ & Information density & Interaction speed/frequency/order/parallelism \\
\hline
\end{tabular}


with mental aspects (relations, thoughts) (cf. [1] [2] [58]). Hence, HCI dimensions represent classes of $\mathrm{HCI}$ variables (expressions of HCI dimensions) useful for the HCI design, which are operationalized by means of (interaction) indicators in HCI metrics. Information speed (speed of dissemination and frequency of occurrence of information), information density (number and distance of information units) or information order (sequence of occurrence and arrangement of information), also correlate with culturally different basic patterns of behavior at the information level [20]. Table 4 shows examples of indicators for some HCI dimensions.

For example, the indicator "number of information units per space unit" belongs to the HCI dimension "information density" and can be expressed by the number of words displayed on the screen. The HCI dimension "interaction frequency" contains the variable "number of interactions per time unit" represented for example by the number of mouse clicks per second. At least one indicator as a measurement variable is necessary to constitute the specifics of an HCI dimension. For real use, however, several empirically proven indicators should be used. If $\mathrm{HCI}$ dimensions are consistently represented based on intercultural variables, one can use "Intercultural HCI Dimensions", which express a culturally influenced HCI style.

\section{Towards a Systematic Approach for IUID}

Due to the lack of sufficient empirical data and the large research gaps remaining in the field of intercultural HCI, it still makes sense to use a basic multi-stage research process based on "Grounded Theory" to develop new theories [20]: Through analytical reflection of already known theories, models and intuitive ideas, hypotheses for a new integration theory can be formed. Then empirical data must establish a foundation (introductory position) to test and verify the hypotheses in order to obtain a new theory. Based on this new theory, new hypotheses and predictions can then be developed in order to test them empirically again (cf. [59]). In an explanatory model for culturally influenced HCI, these relations between culture and $\mathrm{HCI}$ are described using cultural interaction indicators, thus illustrating the relationship between culture and HCI, which can be determined either data-driven or hypothesis-driven as well as by a mixture of both. The data-driven approach first collects data. The resulting patterns provide

Table 4. HCI Dimensions represented by Specifics and Indicators.

\begin{tabular}{|c|c|c|}
\hline HCI Dimension & Specifics & Indicator(s) \\
\hline Interaction frequency & $\begin{array}{l}\text { Number of interactions per } \\
\text { time unit }\end{array}$ & $\begin{array}{l}\text { Mouse clicks and mouse moves per second } \\
\text { or per session }\end{array}$ \\
\hline Information density & $\begin{array}{l}\text { Number of information } \\
\text { units per space unit }\end{array}$ & $\begin{array}{l}\text { Number of words per message or on the } \\
\text { display }\end{array}$ \\
\hline $\begin{array}{l}\text { Information/Interaction } \\
\text { parallelism/order }\end{array}$ & $\begin{array}{l}\text { Sequence of appearance of } \\
\text { information units }\end{array}$ & $\begin{array}{l}\text { Number and sequence of dialog steps (e.g. } \\
\text { number of message boxes used to indicate } \\
\text { one system error) }\end{array}$ \\
\hline
\end{tabular}


information about the connection between culture and HCI. In the hypothesis-driven approach, hypotheses are derived from existing cultural theories and empirically verified afterwards. Finally, in the hybrid approach, the approaches are brought together and, if necessary, extended by additional methods.

\subsection{Data-Driven Approach}

In order to find out where the way in which users from different cultural groups interact with an interactive system is different and to derive possible correlations between cultural dimensions and HCI dimensions, the interaction behavior of users with the computer is observed and analyzed. Using automated analytical tools, dynamic aspects of the HCI can be measured by seamless chronological recording of user behavior (cf. e.g. [60]).

To encourage the culturally different user to interact with the computer and then to record and analyze this interaction, task scenarios were developed which were implemented in a specially developed PC tool (IIA-Tool, [51]). A user test with this tool included several successive parts. First, the demographic data of the subject were collected. Then the task presentation took place: The subject was to perform a series of different tasks, each of which served to examine other cultural aspects of $\mathrm{HCI}$ according to the hypotheses. In order to determine the cultural value of the test person, a questionnaire had to be completed (cf. [37]). The final debriefing clarified the purpose of the test and asked questions about the usability of the test system, the difficulty of the tests and whether the hypotheses had already been guessed during the test (and thus the test validity was lost) or not. By using this tool, parameters relating to the user's interaction with the system are determined. Thereby, this tool allows the measurement of the values of Cultural Interaction Indicators (CIIs), i.e., HCI parameters that correlate with variables representing the user's culture, as well as the expressions of relevant cultural dimensions for the HCI design during the user's interaction with the system by processing test items and applying the VSM94 questionnaire of [37] within the IIA Tool.

For example, the Map Display test case was generated to measure the amount of information on the map display (e.g. restaurants, roads, POIs, etc.) that represents an aspect of information density (Figure 2). The user can set the amount of information in the map display by scrolling (number of POIs, number of maneuvers, etc.). The test tool records the values set by the users. Based on this principle, the test tool can also be used to examine the values of other intercultural variables, such as device position, menu, layout and dialogue structuring, information flow speed, etc. The number, size, distance and uniformity of the arrangement of the information units can be set. In addition, parameters such as test duration, the abruptness and speed of mouse movements, the sequence and speed of controller changes (e.g. scrollbars) and the entire sequence of interactions can be recorded, and average values or maxima and minima can be determined. In addition, measured variables of common usability metrics such as task 


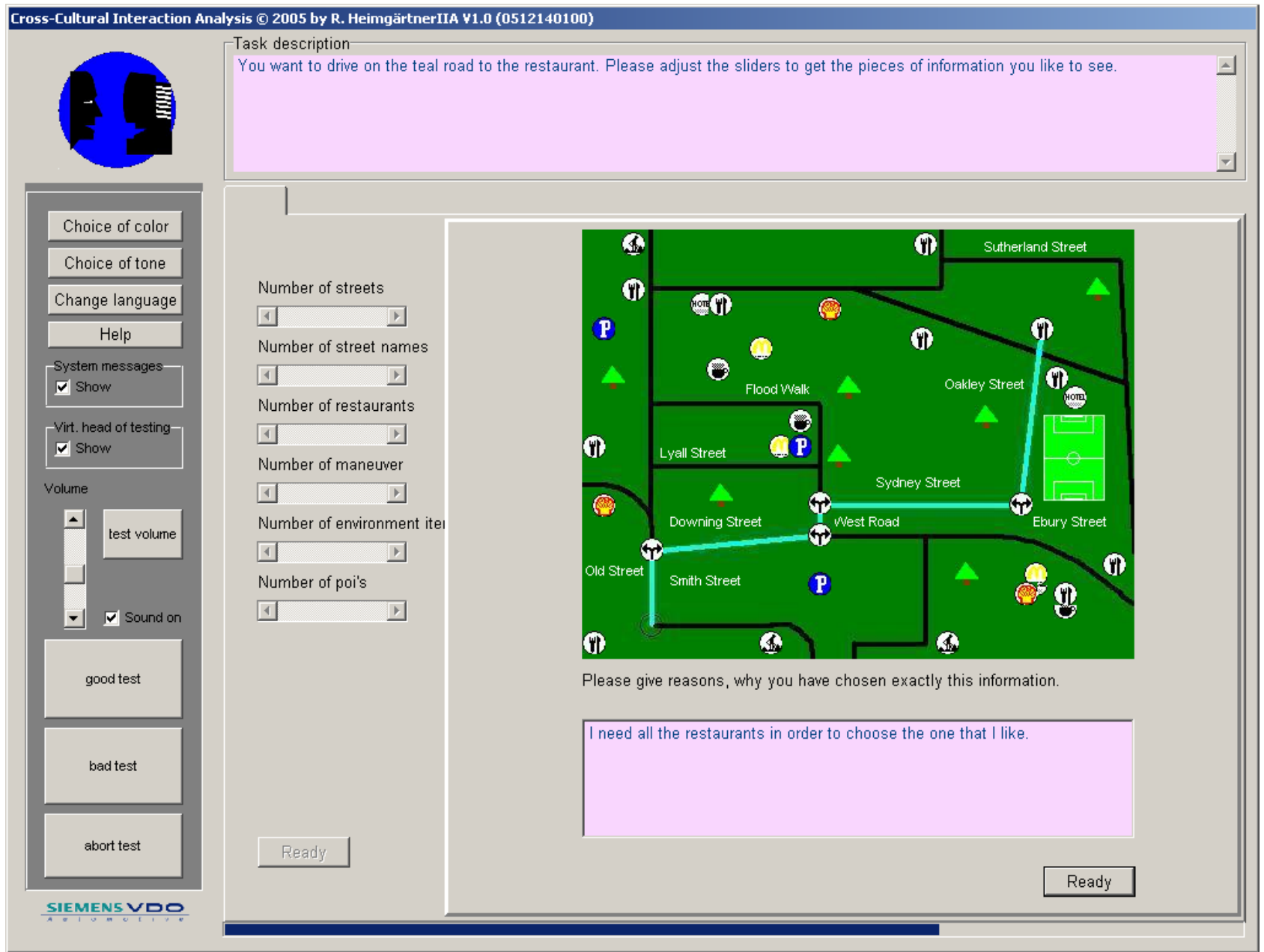

Figure 2. Screenshot of the "Map Display Test Task" during the test session with the IIA Tool.

time, number of errors or number of functions used are recorded [61]. This data shows which correlations occur between the user's interactive behavior and his culture or cultural dimensions and which implications can be derived from this for intercultural HCI design. In 2006 and 2007, two empirical remote online studies with a total of 14,500 Chinese (C), German (G) and English (E) speaking employees of SiemensVDO worldwide collected interaction data and determined which cultural differences in human-computer interaction (HCI) can be quantitatively determined [29].

The evaluation of the data collected in the studies showed that there are correlations between the interaction of users with the computer and the cultural character of users [29]. The cultural interaction indicators found in Table 5 mainly concern the localization level of the interaction.

Significant correlations between culture and HCI could be derived from the cultural interaction indicators obtained from the empirical studies and the cultural interaction patterns (represented by the conglomerate of all constructed cultural interaction indicators, cf. [20]. The high discrimination rate of over $80 \%$ for the classification of users in $(\mathrm{C})$ and $(\mathrm{G})$ by the CIIs proves the validity of the statistical 
Table 5. Cultural differences in the HCI between Chinese (C) and German (G) speaking users.

\begin{tabular}{cc}
\hline Cultural interaction indicator (CII) & $\begin{array}{c}\text { Relationship between Chinese (C) and } \\
\text { German (G) speaking users }\end{array}$ \\
\hline Number of error clicks (clicks without functional effect) & $2: 1$ \\
Number of open applications & $2: 1$ \\
Speed of mouse movements & $1.6: 1$ \\
Number of mouse movements & $1.3: 1$ \\
Number of mouse clicks (left mouse button) & $1.2: 1$ \\
Interaction pauses with the mouse $>10 \mathrm{~s}$ & $1: 1.22$ \\
\hline
\end{tabular}

results. The statistical evaluation of the empirical studies showed significant correlations between the culture of corresponding user groups $((C)$ and $(G)$ ) (defined by demographic variables such as nationality, country of birth and mother tongue and values of HCID: Information density, information and interaction frequency as well as information and interaction parallelism are lower for $(\mathrm{G})$ than for $(\mathrm{C})$ according to the relationship orientation, the density of information networks and the time orientation of the users. The cultural differences in HCI between Chinese and German users concern layout (complex vs. simple), information density (high vs. low), personalization (strong vs. low), language (icons vs. characters), interaction speed (higher vs. lower) and interaction frequency (higher vs. lower) [20]. This fact also seems to be the reason for the significant differences in the use of anthropomorphic agents, relational dialogues and message content as well as chat programs between $(\mathrm{G})$ and $(\mathrm{C})$. According to the empirically determined values of the cultural interaction indicators, the characteristics of the HCI dimensions information frequency, information processing parallelism, information density, interaction speed and interaction frequency are significantly higher for Chinese than for Germans. The numbers in Figure 3 represent the ratio values. For example, the interaction speed at (C) was about twice as high as at $(\mathrm{G})$ : (0.57 to 0.30$)$.

The data-driven approach deals with the correlation of HCI data and demographic variables such as citizenship, mother tongue, country of birth, etc. This is a predominantly descriptive approach in which cultural standards or cultural dimensions are still largely ignored and demographic variables such as nationality or country of birth are used instead. As soon as explanations for the behavior of the user with the system are required from a cultural point of view-as is the case in the hypothesis-driven explanative approach explained in the next section-cultural models must be included in the considerations.

\subsection{Hypothesis-Driven Approach}

The results obtained using the data-driven approach led to the conviction that it is justified and useful to use CIIs for intercultural HCI research in order to obtain 


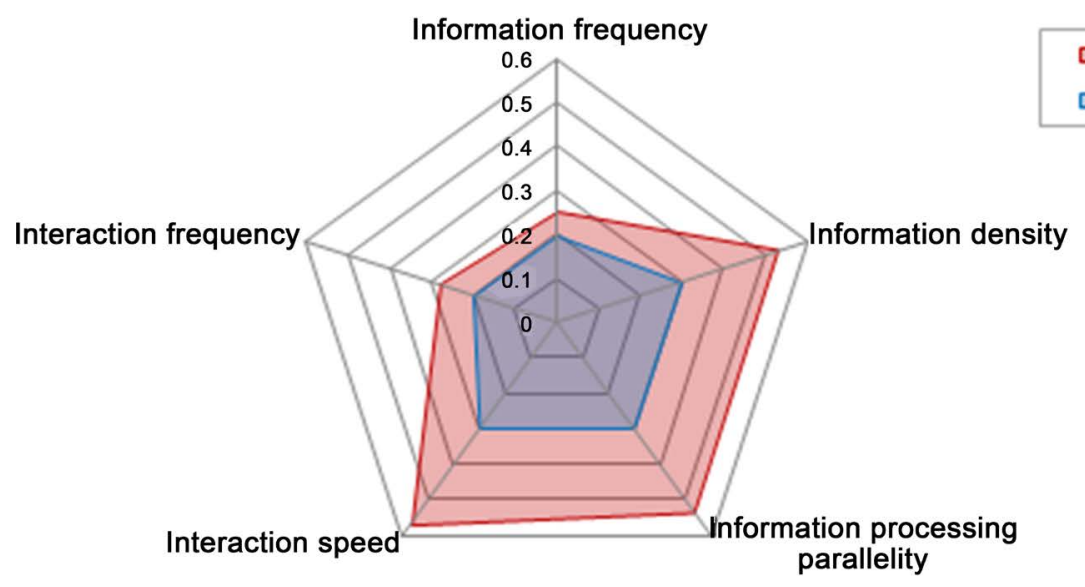

Figure 3. Characteristics of the HCI dimensions representing the culture-dependent differences in the user's interaction with a computer system.

reasonable hypotheses for culturally influenced HCI. Some hypotheses have been developed based on the best classifying CIIs, which is supported by the basic hypothesis that the expressions of the HCI dimensions depend on the cultural imprint of the user as follows: the higher the relational orientation (collectivism), the higher the information density, information speed, information frequency, interaction frequency and interaction speed (and vice versa). [29] examined these hypotheses and confirmed the trend that such relationships exist [20]. Although these findings cannot yet be truly viable prognostic aids within the frame-work of a hypothesis-driven approach (because causal relations have not been identified until now), it is necessary for further research to integrate the tendentious correlations found so far into an initial relationship model in order to be able to use them as a starting point for explanations of the connections between the cultural imprint of the user and his interaction with the system, and thus to establish an initial provisional model of culture-dependent HCI [21]. Table 6 shows possible connections between HCI dimensions, cultural interaction indicators and cultural dimensions or variables of cultural models.

For example, based on the action chain hypothesis [57], it is assumed that the answers to questions from German users are linear (i.e. question after question) and is processed non-linearly by Chinese users (which can be determined by analyzing the mouse movements and the sequence of fields when filling out the questionnaire). Furthermore, the number of dialogue steps until completion of the task could be lower for German users than for Chinese users due to their higher task orientation. For German users it is assumed that the number of interactions during the completion of the task, such as the number of optional functions (e.g. online help or color setup), is higher for German users due to the desire to work very accurately. On the other hand, the number of mouse movements or clicks of German users should be lower than for Chinese users due to the high uncertainty avoidance and strong task orientation. For these reasons, an interaction step during the completion of the task (and thus the entire test duration) might take longer for Germans than for Chinese users. Chinese users may 
Table 6. Cultural interaction indicators and its characteristics representing the relating element between HCI dimensions and cultural dimensions.

\begin{tabular}{llll}
\hline HCI dimension & Cultural interaction indicator & $\begin{array}{l}\text { Examples/characteristics of cultural } \\
\text { interaction indicators }\end{array}$ & $\begin{array}{l}\text { Cultural dimension/variables } \\
\text { of cultural models }\end{array}$ \\
\hline Information frequency & $\begin{array}{l}\text { Number of information units per time } \\
\text { unit }\end{array}$ & $\begin{array}{l}\text { Number of words, sentences, dialogues, } \\
\text { propositions etc. per minute, reference } \\
\text { distance }\end{array}$ & $\begin{array}{l}\text { Uncertainty, avoidance, action } \\
\text { chains, network density }\end{array}$ \\
Information density & $\begin{array}{l}\text { Distance of information units from each } \\
\text { other, number of simultaneously } \\
\text { presented information units }\end{array}$ & $\begin{array}{l}\text { Picture-text ratio, number of places of } \\
\text { interest }\end{array}$ & $\begin{array}{l}\text { Uncertainty avoidance, } \\
\text { network density }\end{array}$ \\
Information or & $\begin{array}{l}\text { Sequential or parallel, presentation or } \\
\text { interactional parallelism } \\
\text { reception of information units, } \\
\text { information arrangement }\end{array}$ & $\begin{array}{l}\text { Number of parallel tasks, discarded system } \\
\text { messages, time until deactivation of virtual } \\
\text { agents, layout }\end{array}$ & $\begin{array}{l}\text { Mono-chronic vs. poly-chronic } \\
\text { time orientation, }\end{array}$ \\
& $\begin{array}{l}\text { Duration of an interaction process } \\
\text { Interaction speed }\end{array}$ & $\begin{array}{l}\text { Mouse usage, mouse motion pauses less than } \\
1 \text { ms, mouse track length per second, inputs }\end{array}$ & $\begin{array}{l}\text { Mono-chronic vs. poly-chronic } \\
\text { time orientation }\end{array}$ \\
Interaction frequency & $\begin{array}{l}\text { Number of interaction processes per } \\
\text { time unit }\end{array}$ & $\begin{array}{l}\text { Number of mouse clicks, mouse movements, Mono-chronic vs. poly-chronic } \\
\text { function or help initiatives per session }\end{array}$ & time orientation
\end{tabular}

not use the help button as often as German users due to face-saving (see [45]). The speed of mouse movements could be lower for German users due to high uncertainty avoidance and low communication speed or low context and relationship orientation.

Some of the postulated connections between culture and HCI known from the literature were examined repeatedly with the help of the specially developed tool for intercultural interaction analysis (IIA Tool, [51]). The hypotheses were tested, for example again within the "Map Display Test Task" as described before, by presenting the same task to subjects from different cultures. For example, the hypothesis "there is a high correlation of high information density to relation-oriented cultures such as Chinese" could be confirmed by the choice of more POIs by German users compared to Chinese users. Moreover, the results of the investigation based on the differences in the effective values of the measurement variables in contrast to the values of the parameters assumed in the hypotheses supported these results. For example, it was assumed that the number of interactions with the system per time unit (INH) of Chinese users is about four times higher than that of German users $(0.8: 0.2=4)$. However, the ratio is only 1.4 with respect to the number of average mouse movements in a test session (10,566:7529). This ratio is an indicator of the strength of the postulated hypothesis. The confirmation strengths of six out of eight hypotheses were estimated a priori approximately correctly, and all postulated eight hypotheses were confirmed a posteriori using the online studies with the IIA tool. This shows that the analytical preparatory work and the methods and tools used in the studies were appropriate and that the results can be considered plausible and correct [20].

\subsection{Hybrid Approach}

The hybrid approach integrates both approaches applying several IUID methods 
within an IUID method mix [21]. Based on the method of the culture-oriented HCI design (MCD, see [2]), cultural differences are identified based on cultural dimensions and cultural variables are derived for the project. With this knowledge of cultural differences and affected aspects of the HCI system, further effects on the HCI design are determined and supported by hypothesis-driven data transmission using user interface characteristics (see [62]) and HCI dimensions (see [20] by a "toolbox" for IUID consisting of a reasonable arranged method mix, (cf. [21]). The method mix consists of a combined and hybrid use of cultural dimensions, intercultural variables, user interface characteristics, and $\mathrm{HCI}$ dimensions. The values of these concepts represent the HCI style of the user in the respective cultural context.

One important goal for intercultural HCI designers and intercultural usability experts is to consider fundamental cultural differences when dealing with members of cultures interacting with machines. Hence, the most important step is to bridge the gap between cultural aspects (formally derived from cultural dimensions) and HCI design by determining relevant cultural parameters for intercultural user interface design using analytical research tools and empirical tests. These tests should show whether human-machine interaction runs parallel to cultural dimensions, and if so, to what extent. Cultural models and cultural interaction indicators, which have been generated by the analysis of user interaction, can be used to describe the needs of the user in terms of the HCI depending on his culture as well as to develop an explanatory model for culturally influenced HCI and to improve the methods of intercultural usability engineering. With the help of an explanatory model of culture-dependent HCI, examples of different culturally conditioned behavior of users can be explained with interactive systems. For this purpose, the explanatory models must be determined on the basis of analytical considerations and verified using empirical data and statistical methods. Due to the lack of existing modeling and available cultural HCI theories, an iterative, i.e. alternately analytical and empirical approach is necessary (i.e. alternately data- and hypothesis-driven), so that an "evolutionary explanatory model" gradually emerges.

Successful explanatory models can be applied to new examples or application cases and thus verified, which in turn allows predictive design recommendations to be generated. Finally, complete metrics for representing the usability of interactive systems (usability measurement systems, cf. [63]) can be derived from high empirical values for the culturally influenced HCI. In order to measure the parameters, the characteristics of the HCI dimensions must be very precise and concrete. Therefore, the HCI dimensions are operationalized in many quantitative variables in order to obtain a basic measurement instrument and link it to cultural dimensions, thus generating empirical hypotheses.

The results found in the hypothesis-driven approach also led to the conviction that it is justified and useful to use cultural interaction indicators for intercultural HCI research in order to obtain a reasonable explanatory model for culturally 
influenced HCI. For this reason, initial considerations were made which reflect the relationships between the HCI dimensions and cultural aspects. Thereby, the following hypotheses have been postulated:

- Hypothesis 1: In relationship-oriented countries with high density of communication networks, communication speed, and high context orientation (e.g., China), it is the case that information flow, frequency, and density as well as interaction speed and frequency are high. In task-oriented countries with low density of communication networks, communication speed, and low context orientation (e.g., Germany), information flow, frequency, and density as well as interaction speed and frequency are low.

- Hypothesis 2: In countries with poly-chronic time orientation and low uncertainty avoidance (e.g., China), information and interaction parallelism are high. In countries with mono-chronic time orientation and high uncertainty avoidance (e.g., Germany), information and interaction parallelism are low.

The aim was to find out the actual connection between the interaction indicators and their (postulated cultural) causes representing the relationships between cultural dimensions and HCI dimensions and their expressions. To solve this, a structural equation model for the relationship between HCI dimensions and cultural dimensions has been generated. The connections between cultural, information-related and interaction-related dimensions were modeled using the cultural interaction indicators. The explanatory model of culture-dependent $\mathrm{HCI}$ is all the better the more variances in the empirical data can be statistically explained by the modeled structural equations. For this, a partial model of one side of a complete structural equation model, which has emerged from literature studies, postulated hypotheses in [29] and empirical results from [20] was modeled in AMOS. Table 7 shows the resulting relations between cultural and HCI dimensions represented by cultural interaction indicators indicating the culturally different HCI style between Chinese (C) and German (G) speaking users expressed by the quantified ratio of the CIIs between (C) and (G).

Other combinations of cultural interaction indicators (CIIs) are also possible for the allocation to HCI dimensions. The explanatory model is based on some of the best-classifying cultural interaction indicators from the data-driven approach, which have emerged from the hypothesis in the hypothesis-driven approach, namely that the expressions of the HCI dimensions depend on the cultural imprint of the users, which can be described by the expressions of cultural dimensions: the higher the relationship orientation (collectivism), the higher the information density, information speed, information frequency, interaction frequency and interaction speed (and vice versa).

The empirical findings from the study in the data-driven approach and the hypotheses derived from the hypothesis-driven approach (the higher the relationship orientation, the higher the information density, information speed, etc.) are reflected by corresponding trends in the parameter values of the structural equation model (hybrid approach). This supports the assumption that further connections between cultural dimensions and HCI dimensions and cultural 
Table 7. Quantified Ratio of the CIIs representing the cultural distance between cultures (according to [20]).

\begin{tabular}{|c|c|c|c|c|}
\hline HCI Dimension & $\begin{array}{l}\text { Ratio of } \\
(\mathrm{C}):(\mathrm{G})\end{array}$ & Cultural interaction indicator (CII) & Examples & Cultural dimension \\
\hline Information frequency & 1.25 & $\begin{array}{l}\text { Distance between notes, number of } \\
\text { information units per time unit }\end{array}$ & $\begin{array}{l}\text { Number of words, sentences, } \\
\text { dialogues, propositions etc. } \\
\text { per minute }\end{array}$ & $\begin{array}{l}\text { Uncertainty avoidance, action } \\
\text { chains, network density }\end{array}$ \\
\hline Information density & 1.77 & Number of places of interest & $\begin{array}{l}\text { Picture-text ratio, distance of } \\
\text { information units from each other, } \\
\text { number of simultaneously } \\
\text { presented information units }\end{array}$ & $\begin{array}{l}\text { Uncertainty avoidance, network } \\
\text { density }\end{array}$ \\
\hline $\begin{array}{l}\text { Information and } \\
\text { interaction parallelism }\end{array}$ & 1.61 & $\begin{array}{l}\text { Number of parallel tasks, rejected } \\
\text { system messages, time to deactivate } \\
\text { the virtual agent ("life-like } \\
\text { character", e.g. "Merlin" in Word) }\end{array}$ & $\begin{array}{l}\text { Sequential or parallel presentation } \\
\text { or reception of information units } \\
\text { and information arrangement (e.g. } \\
\text { layout) }\end{array}$ & $\begin{array}{l}\text { All time-relevant cultural } \\
\text { dimensions (such as uncertainty } \\
\text { avoidance, action chains or time } \\
\text { orientation) }\end{array}$ \\
\hline Interaction speed & 1.89 & $\begin{array}{l}\text { Mouse motion pauses less than } 1 \\
\mathrm{~ms}\end{array}$ & $\begin{array}{l}\text { Mouse usage, keyboard entries, } \\
\text { length of mouse track per time unit }\end{array}$ & $\begin{array}{l}\text { All time-relevant cultural } \\
\text { dimensions }\end{array}$ \\
\hline Interaction frequency & 1.41 & $\begin{array}{l}\text { Mouse clicks with left mouse } \\
\text { button, number of mouse } \\
\text { movement events }\end{array}$ & $\begin{array}{l}\text { Total number of mouse clicks/ } \\
\text { mouse movements or number of } \\
\text { function or help initiatives per } \\
\text { session }\end{array}$ & $\begin{array}{l}\text { All time-relevant cultural } \\
\text { dimensions }\end{array}$ \\
\hline
\end{tabular}

interaction indicators can be modeled and explained using structural equation models as a basis for the application of the IUID method-mix. Based on $\mathrm{H} 1$ and $\mathrm{H} 2$, a model of culturally influenced $\mathrm{HCI}$ can be created containing the relationships between cultural dimensions and HCIDs. The entire model for culturally influenced $\mathrm{HCI}$ consists of more than 300 , mainly quantitative, potential parameters that are relevant for intercultural $\mathrm{HCI}$ design and, depending on the culture, have been analytically established by the literature study (cf. for details [20]). The model contains the following rules expressing the connection between the values of the cultural dimensions and the values of the HCIDs, thereby determining the denotation level for culture and HCI (cf. for details [21]):

1) The lower action chain orientation:

a) the higher information frequency.

b) the higher information and interaction parallelism.

c) the higher interaction frequency.

2) The lower the IDV:

a) the higher information frequency.

b) the higher interaction frequency.

3) The lower the UAI:
a) the higher information frequency.
b) the higher interaction frequency.
c) the lower interaction exactness.

4) The lower the MAS:

a) the higher information density.

b) the higher information frequency.

c) the higher interaction frequency. 
5) The higher network density and context orientation:

a) the higher information density.

b) the higher information and interaction parallelism.

c) the higher interaction frequency.

d) the higher interaction speed.

e) the lower interaction exactness.

6) The higher LTO:

a) the higher information frequency.

b) the higher interaction speed.

7) And vice versa for all rules (i.e., for Rule 1: the lower action chain orientation, the higher information/interaction frequency and parallelism).

According to the changed values of the cultural dimensions on the left side of the model (antecedences in the production rules above), the values of the HCIDs change on the right side of the model (consequences in the production rules above). Therefore, this model does not depend on nations or countries but can be used to cover every cultural group (with at least 20 members if using the VSM to determine the cultural characteristics of the group, cf. [37]). These results lead the author to the concept of intercultural HCI style scores, which can be computed for the designated cultural group from Hofstede's indices. The intercultural HCI style score expresses the average degree of information density and frequency as well as interaction frequency and speed the members in the designated cultural group expect according to the model developed by the author (cf. Table 8).

The HCI style score is computed using the following formula according to the rules in the model described above (cf. Equation (1)).

$$
\text { HCI Style } \mathrm{Score}_{\text {S }}=\mathrm{IDV}_{\text {Score }}+\mathrm{MAS}_{\text {Score }}+\mathrm{UAI}_{\text {Score }}-\mathrm{LTO}_{\text {Score }}
$$

Equation (1) just approximately approaches reality because there are more rules that should be integrated (such as rules 1 and 6). This HCI style score in Equation (1) expresses the average degree of information density and frequency as well as interaction frequency and speed the members in the designated cultural group expect according to the specified rules in the model just presented. For instance, the lower the normalized HCI style score (ranging 0-100) the lower the

Table 8. HCI Styles around the World. Anglo-Saxon, German, Asian, South American, Slavic and Scandinavian.

\begin{tabular}{clc}
\hline HCI style & \multicolumn{1}{c}{ Cultural characterization } & Normalized HCI Style Score (group averaged) \\
\hline Asian & PDI high, IDV low, MAS middle, UAI low, LTO high & 90 \\
South American & PDI high, IDV low, MAS middle, UAI middle, LTO low & 60 \\
Scandinavian & PDI low, IDV high, MAS low, UAI middle, LTO low & 40 \\
Slavic & PDI high, IDV middle, MAS middle, UAI high, LTO low & 30 \\
Angle-Saxon & PDI low, IDV high, MAS middle, UAI low, LTO low & 20 \\
German & PDI low, IDV middle, MAS high, UAI middle, LTO high & 10 \\
\hline
\end{tabular}


expected amount of information and the lower the interaction frequency. The resulting HCI style scores permit the establishment of clusters of countries that have similar HCI scores. According to these cultural clusters identified in the HCI style score continuum, it can be expected that these country clusters exhibit a similar HCI style because of their similar cultural characterization defined by PDI, IDV, MAS, UAI, and LTO. This tendency helps the practitioner to determine the effort needed for IUID for the desired culture.

\subsection{IUID Method-Mix from the Hybrid IUID Approach as a First Step towards a Systematic Approach for IUID}

The procedure to derive design recommendations for IUID from scratch is as follows: First, the application, main uses cases and the desired target cultures are chosen. Depending on the use case, the respective UI elements (e.g. layout, buttons, text fields) have to be determined and mapped to the category of the cultural variables (direct, indirect, visible, hidden) as well as to the user interface characteristics (presentation, interaction, navigation, mental model and metaphor). Using this information, the time and space related HCI dimensions concerned must be analyzed (such as information density or interaction frequency). Via the rules and the variables in the explanatory model for culturally influenced $\mathrm{HCI}$, the detected $\mathrm{HCI}$ dimensions can be related to the cultural dimensions in order to obtain the related cultural interaction indicators. Recommendations for the design of intercultural user interfaces can be drawn as well. Table 9 shows the results obtained by the application of this systematic procedure using the IUID method mix.

The value of the cultural dimensions can be looked up in the literature of cultural research (as absolute numeric values from [32] or [64] or as relative categorial numbers by other authors of cultural dimensions such as [40]). For example, if individualism in a culture is low (e.g. for China (IDV $=20$ ) in contrast to Germany (IDV $=67$ ) according to [32], then information frequency and interaction frequency tend to be high (e.g. for China in contrast to Germany according to [20]). Another example: the higher the density of an information network (e.g. as in China compared to Germany according to [40]), the stronger the values of the HCI dimensions are (such as information density and interaction frequency) according to [20].

Assume, a UI designer wants to identify design recommendation for IUID for users from China or Germany regarding an application with the use case "sending a short text message via SMS on a mobile phone" (cf. last example in Table 9). The first step is to identify the cultural dimensions representing the highest cultural distance between the target cultures. According to Hofstede's cultural compass, these are power distance, individualism and uncertainty avoidance (cf. Figure 4, retrieved from

https://www.hofstede-insights.com/product/compare-countries/, last access 5|4|2019).

The next step is to identify the UI elements (e.g. text, characters, character set, 
layout) that are concerned in the use case and to relate them to the user interface characteristics (e.g. presentation). Now, the mapping of the UI characteristics to the cultural variables is to be done. Presentation concerns direct, visible cultural variables on the surface of the user interface (such as language, color, layout). The relationship between cultural dimensions and HCI dimensions comes into play by following the rules of the explanatory model expressing the connection between the values of the cultural dimensions and the values of the HCIDs. IDV is related to information and interaction frequency. UAI is related to information and interaction frequency as well as to interaction exactness. Furthermore, HCIDs are also related to UI characteristics. For example, information density is affected by the cultural presentation requirements (cf. culturally different communication patterns, [65]). This different communication behavior can be expressed using adequate cultural interaction indicators such as number of pieces

Table 9. Application of the IUID method mix (extract of the results from IUID method mix workshops by the author).

\begin{tabular}{|c|c|c|c|c|c|c|}
\hline $\begin{array}{l}\text { Application/ } \\
\text { Use Case }\end{array}$ & $\begin{array}{l}\text { Cultural aspect/ } \\
\text { Cultural } \\
\text { dimension }\end{array}$ & $\begin{array}{l}\text { UI } \\
\text { characteristics }\end{array}$ & $\begin{array}{l}\text { Cultural } \\
\text { variable }\end{array}$ & HCI dimension & $\begin{array}{l}\text { Cultural } \\
\text { interaction } \\
\text { indicator }\end{array}$ & $\begin{array}{l}\text { IUID } \\
\text { implication }\end{array}$ \\
\hline $\begin{array}{l}\text { Word processing/ } \\
\text { Filling in a form }\end{array}$ & $\begin{array}{l}\text { Language/ } \\
\text { Communication } \\
\text { network density }\end{array}$ & $\begin{array}{l}\text { Presentation, } \\
\text { interaction }\end{array}$ & $\begin{array}{l}\text { Direct (word } \\
\text { length), layout }\end{array}$ & $\begin{array}{l}\text { Information density, } \\
\text { interaction frequency }\end{array}$ & $\begin{array}{l}\text { Average number } \\
\text { of chars per } \\
\text { word, page }\end{array}$ & $\begin{array}{l}\text { Resizing, calculate size of } \\
\text { display according to } \\
\text { language }\end{array}$ \\
\hline $\begin{array}{l}\text { E-learning } \\
\text { system/Learning } \\
\text { content }\end{array}$ & $\begin{array}{l}\text { Communication } \\
\text { speed, power } \\
\text { distance, } \\
\text { uncertainty } \\
\text { avoidance }\end{array}$ & $\begin{array}{l}\text { Presentation, } \\
\text { navigation }\end{array}$ & $\begin{array}{l}\text { Visible } \\
\text { (character set, } \\
\text { buttons) }\end{array}$ & $\begin{array}{l}\text { Information } \\
\text { presentation speed }\end{array}$ & $\begin{array}{l}\text { Dialogues per } \\
\text { minute, number } \\
\text { of breaks in } \\
\text { interaction }\end{array}$ & $\begin{array}{l}\text { Adapt speed of guided } \\
\text { dialogues (wizards) and } \\
\text { button size }\end{array}$ \\
\hline $\begin{array}{l}\text { Phone/Looking } \\
\text { up dialing via } \\
\text { name or number }\end{array}$ & $\begin{array}{l}\text { Communication } \\
\text { speed, density of } \\
\text { the information } \\
\text { network }\end{array}$ & $\begin{array}{l}\text { Interaction, mental } \\
\text { model }\end{array}$ & $\begin{array}{l}\text { Indirect (online } \\
\text { operating } \\
\text { manual) }\end{array}$ & $\begin{array}{l}\text { Interaction speed and } \\
\text { interaction style }\end{array}$ & $\begin{array}{l}\text { Number of } \\
\text { buttons presses } \\
\text { per task }\end{array}$ & $\begin{array}{l}\text { Choose appropriate } \\
\text { input method editor } \\
\text { (IME) and sorting } \\
\text { algorithms }\end{array}$ \\
\hline $\begin{array}{l}\text { Word processor } \\
\text { on a mobile } \\
\text { phone/Sending a } \\
\text { short text message } \\
\text { via SMS }\end{array}$ & $\begin{array}{l}\text { Power distance, } \\
\text { individualism, } \\
\text { uncertainty } \\
\text { avoidance }\end{array}$ & $\begin{array}{l}\text { Presentation: text, } \\
\text { character, character } \\
\text { set, layout, skin, } \\
\text { edit field, send } \\
\text { button, receiver list } \\
\text { box }\end{array}$ & $\begin{array}{l}\text { Direct, visible, } \\
\text { surface (color, } \\
\text { skin, language) }\end{array}$ & $\begin{array}{l}\text { Information density, } \\
\text { interaction frequency } \\
\text { and speed, Information } \\
\text { and interaction } \\
\text { parallelism, interaction } \\
\text { exactness }\end{array}$ & $\begin{array}{l}\text { Number of pieces } \\
\text { of information } \\
\text { per space, } \\
\text { number of SMS } \\
\text { per day, } \\
\text { number of saved } \\
\text { contacts }\end{array}$ & $\begin{array}{l}\text { Adapt system } \\
\text { memory/choose } \\
\text { appropriate input } \\
\text { method editor (IME) and } \\
\text { sorting algorithms/allow } \\
\text { customization of the } \\
\text { number of entries in lists }\end{array}$ \\
\hline
\end{tabular}

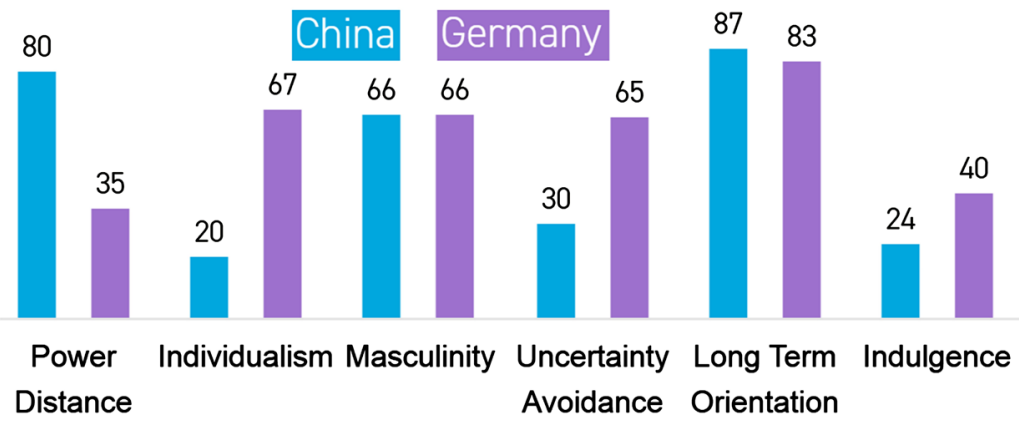

Figure 4. Hofstede's cultural dimensions and their values for China and Germany. 
of information per space, number of SMS sent per day or number of contacts, which in turn leads to the following requirements for system design and recommendation for IUID: An HCI-System needs to have enough memory for storing contacts and sent short messages. Furthermore, it needs an input method editor for the different character sets in China and Germany in order to quickly choose and select the desired receiver name from an adequately sorted list. The user interface should be customizable to the number of presented pieces of information, e.g., the number of entries in lists or menus (cf. hierarchical versus flat menu structure, [66]). Finally, from Hofstede's data, one can infer that the cultural distance between China and Germany is high in contrast to Austria and Germany, which is also reflected in the HCI style score (cf. Table 8) and therefore in the behavior of the user interaction with the system. The HCI style score for a country is computed as follows:

1) Use Equation (1) for the desired countries delivered by Hofstede. For example, HCI Style Score ${ }_{\text {China }}$ is $20+66+30-87=29$, HCI Style Score $_{\text {Austria }}$ is 55 $+79+70-60=144$ and HCI Style Score Germany $_{\text {is }} 67+66+65-83=115$.

2) Identify the minimal and the maximal HCI Style Score. This step ensures that cultural changes over time (cf. [48]) are considered in the HCI Style Scores. According to the latest empirically determined values by [38], published on the Website by Hofstede

(URL $=$ https://www.hofstede-insights.com/product/compare-countries/, last access 5|4|2019), the HCI Style Score Max is 192 and HCI Style Score Min is 4.

3) Normalize the range between the minimal and the maximal HCI Style Score to the range of $0-100$, using the following equations:

a) HCI Style Score Range $e_{\operatorname{Max} / \text { Min }}=$ HCI Style Score Max - HCI Style Score Min.

i) HCI Style Score Range $\mathrm{Max}_{\mathrm{Min}}=192-4=188$.

b) HCI Style Score Range $e_{0-100}=$ HCI Style Score $100-$ HCI Style Score 0.

i) HCI Style Score Range $e_{0-100}=100-0=100$.

c) HCI Style Score Range $\mathbf{N}_{\text {ormalizing Factor }}=$ HCI Style Score Range Max $/ \mathrm{Min} / \mathrm{HCI}$ Style Score Range 0 -100.

i) HCI Style Score Range Normalizing Factor $=188 / 100=1.88$.

4) Recalculate the HCI Style Score Values for all countries for the new range $(0-100)$ using the following equation (use additionally rounding to get integer values if desired): HCI Style Score $e_{\text {Range } 0-100}$ Country $\mathrm{x}=($ HCI Style Score Range Max/Min Country $\mathrm{x}$ - HCI Style Score Min)/HCI Style Score Range Normalizing Factor

5) Invert the values of the HCI Style Score for every country using the following equation to mirror the relationship between the cultural and HCI dimensions from the model of culture-dependent HCI above: HCI Style Score Country $\mathrm{X}_{=}$ 100 - HCI Style Score country $_{\text {. }}$

Using these equations, the HCI Style Scores for 60 countries have been calculated and clustered according to their score distances, e.g. HCI Style Scores for Austria, Germany and China are 26, 41 and 87 (cf. Figure 5). The analysis of the values of the cultural dimensions of Hofstede confirms the tendency that the 
countries can be clustered depending on their cultural behavior representing the cultural distances between the clusters: Anglo-Saxon, German, Asian, European, South American and Scandinavian. These results support the HCI style groups (cf. Table 8) and the taxonomic results in the intercultural HCI styles partially resembles the findings of [67] on "Saxonic", "Teutonic", "Gallic" and "Nipponic" styles. By analyzing these HCI Style Scores, it is possible to draw conclusions about the number of design recommendations and the effort to implement them for the desired target culture. This allows a project manager to plan the most important work packages and do the related time and cost estimations for future intercultural user interface projects in advance.

\section{Discussion}

The results so far (postulated and confirmed hypotheses) serve to reveal a basis and some proven facts that are useful for the acquisition of general recommendations for trends in intercultural HCI design and for the culturally-adaptive systems (cf. [20]). The IIA tool [51] served to record and analyze the user's interaction with the system to identify culturally influenced variables such as color, positioning, information density, and interaction speed as well as their values, which enabled the verification of parts of the culture-dependent model of $\mathrm{HCI}$ as well as preliminary design rules for intercultural HCI design ([20]). Cultural interaction indicators (CIIs) serve to determine along cultural imprint also computer experience, age, gender etc., which is mostly relevant for building user models necessary for adaptive systems. Real cultural classification works because the variables (CIIs) can be selected according to the expected definition of culture (e.g., nationality). This means that with the right combination of CIIs it is possible to get interaction differences that are really purely culturally imprinted ([20]). The developed metrics consisting of the most discriminating CIIs is adequate to measure cross-cultural HCI in culturally adaptive systems ([20]). In addition, the cultural differences in HCI found are measurable quantitatively by a computer system using special combinations of CIIs represented by cultural interaction patterns (CIPs) (cf. HCI styles) depending on the culturally imprinted interaction behavior of the user. Thereby, the analysis (recognition and classification) of cultural interaction patterns in $\mathrm{HCI}$ can be achieved purely quantitatively and cultural differences in HCI can be analyzed quantitatively ([20]). A handful CIIs is sufficient for this purpose. Moreover, the cultural interaction patterns representing the cultural differences in $\mathrm{HCI}$ and the derived CIIs are sufficiently statistically discriminating enough to detect them and to relate the users to a certain cultural imprint (cf. [20]).

However, according to [68], the methodological problem of research on culture is that the transmission of simple systems is easier than the integration of complex systems, which can only be achieved by human creativity. This applies primarily to cultural questions, which encompass and integrate the complete context of a member of a culture. This problem also confronts intercultural 


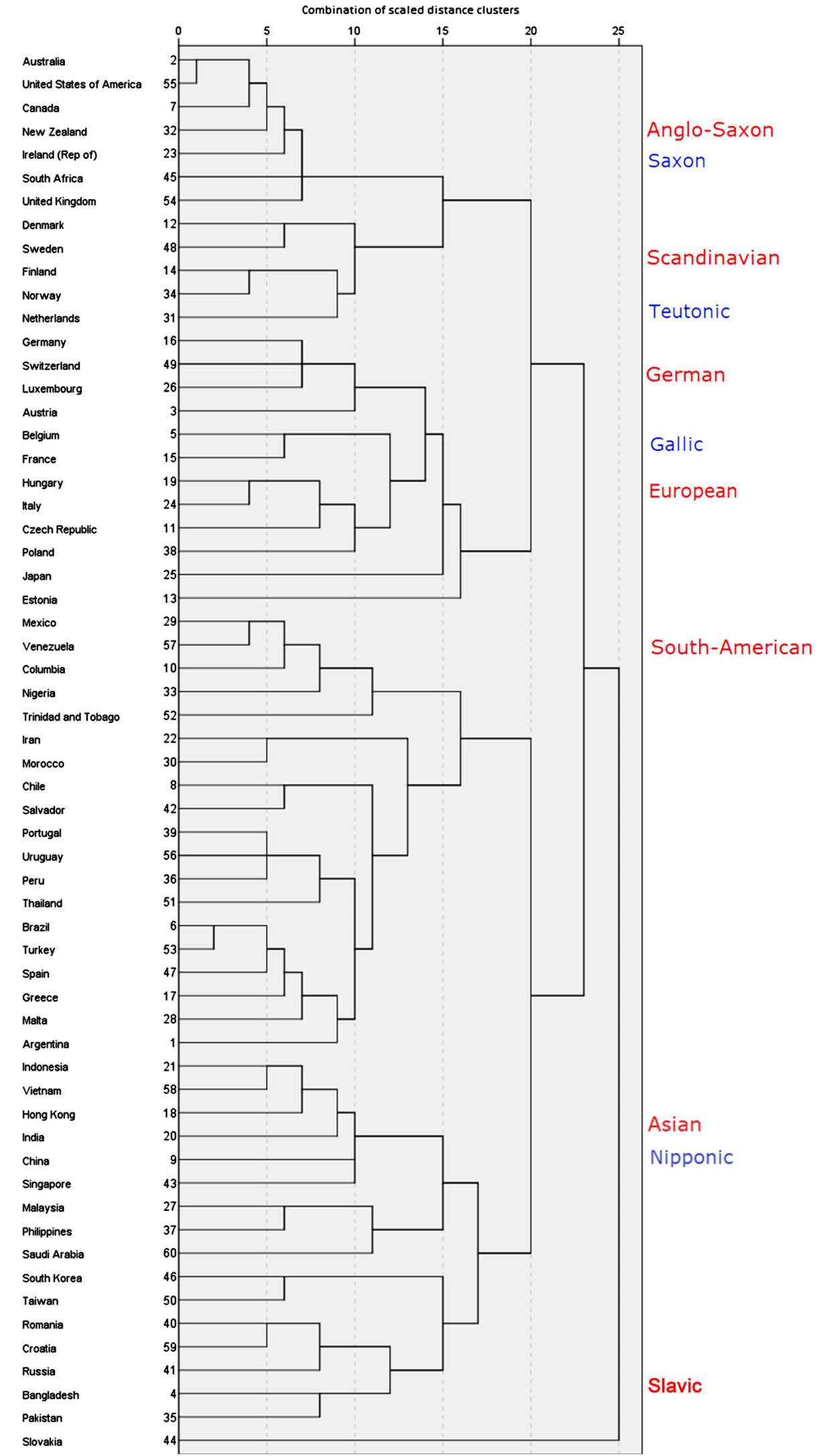

Figure 5. Cultural distances according to the values of the six cultural dimensions of Hofstede (combination of scaled distance clusters). 
user interface design, which makes it compellingly necessary to deal with the combination or linkage of culture with HCI design.

\subsection{Lack of Empirical Confirmation}

Not all recommendations have yet been proved empirically according to the five areas of user interface characteristics, even if there is some research in this area. [69] validated some of the aspects pointed out by Marcus doing qualitative studies in China regarding different layouts for Chinese and German users. Moreover, regarding metaphors it is the case that in China hierarchical taxonomies and classifying instruments are applied rather than the case in Germany because of the high-power distance values. Most of the recommendations presented must be tested and confirmed empirically in detail by additional studies before being suggested as best practices or even useful guidelines, if not already done so. Furthermore, parallel to the research literature, empirical investigations regarding intercultural user interface characteristics are necessary, more specifically by comparing several systems of different cultures (benchmark tests) as well as usability evaluation (usability testing). For example, it has also been empirically shown that user interaction with the system is influenced not only by culturally related variables such as nationality, mother tongue, country of birth, etc., but also by parameters such as experience and age [29]. The separation degree of the variables must be improved by future research (e.g., by extending the number of considered cultural dimensions).

\subsection{Usage of Cultural Dimensions}

On the one hand, critics of Hofstede claim that the samples drawn from IBM's worldwide employee interview in their original study of 1967-72 are not representative. They do not provide data for measuring national culture differences between the countries but rather the differences within the corporate culture of IBM. Furthermore, Hofstede's approach ignores differences within a nation. However, according to [70], restricted appreciation and mediation of cultural dimension and models can lead to ineffective or even restricting action strategies. In this case, a little cultural understanding proves to be just as bad as or even worse than no cultural understanding at all. Therefore, [70] pleads for dimension independent cultural models because they make the derivation of concrete behavior patterns possible whose explanations are founded on concrete manifestations of the culture by contrast to models that use cultural dimensions. This approach is addressed in the revised principle of culturally-adaptive HMI [cf. 20] abstaining from cultural categorization. The developed rules within the presented model above still describes the assumed relationship between cultural dimensions and HCI dimensions. Until these assumed connections are not completely empirically verified, the model remains hypothetical. Therefore, much research effort is still necessary because of the number and complexity of the relationships in HCI determined by culture. Nevertheless, it is a possible step 
on the path toward a model of culturally influenced HCI that must be verified, refined, and optimized step by step over time to prove its value.

\subsection{Methodological and Empirical Problems of Modeling}

Many aspects must be considered simultaneously to obtain possible cultural explanations for their effect on HCI. Alternatively, the effects of culture on HCI cannot be explained by only one single aspect but by many different influences due to the complexity of culture. Another problem in cultural research is that one cannot predict how the single parts of the cultural puzzle will fit together (cf. [68]: 130). This has implications for the use of these methods in intercultural $\mathrm{HCI}$ design and intercultural usability engineering (cf. [71]). It is problematic to bring cultural models fully in line with HCI dimensions, as not all possible interfering variables can be considered due to cultural complexity and models cannot fully describe reality because of their nature. It is difficult to separate cultural influences from experience, because experience is also culturally shaped. The results obtained by the explanatory model therefore also differ from reality. Further modeling must show which cultural interaction indicators and which of their combinations will provide the highest quality of explanation. More detailed studies are therefore needed in order to further verify, refine and optimize such an initial explanatory model. Nevertheless, it is very reasonable for further development and research to consider some rules of thumb, even if they must be considered provisional and should therefore still be treated with the greatest possible care.

\subsection{Vagueness of HCI Styles}

The average HCI style score of the designated cultural group can be computed from the model represented only by those rules for which Hofstede's indices are known. For rules 2, 3, 4, and 6 presented previously, the indices IDV, UAI, MAS, and LTO can be used to integrate these rules with exact values from the indices and thereby to calculate the HCI style score. Further modeling still must show which of the possibilities are the most significant and useful. In addition, the other side of the structural equation model must also be explored more closely, on which the cultural dimensions must be introduced and linked. However, until there are no other values for the cultural dimensions than Hofstede's at the national level, those must be used to test the model. In addition, to further confirm findings, factor analysis can be applied to statistically calculate the corresponding loadings to the HCI style by clustering Hofstede's indices according to their HCI style score. The findings should refine the currently assumed rules that describe the relationship between cultural imprint and HCI style of a group. The explanatory value of this descriptive model must still be worked out. To generalize the postulated correlations, many more studies with other cultural groups are required. To achieve this both the values of the cultural dimensions (e.g., using VSM) and the values of the HCIDs (such as pieces of presented in- 
formation per minute; [20]) must be determined. This can be done using the same use cases and test settings in the arbitrary cultural groups of interest, for example, also for indigenous groups. The test tool developed by the author can be used to support this [51]. Finally, to generalize the postulated correlations many more studies with other cultural groups are required.

\subsection{Testing the Explanation Model}

The following steps help to verify the model: 1) Reviewing literature about different cultures and extraction of HCI data from those cultures (by empirical studies using the intercultural interaction analysis tool as done in [20]). 2) Identifying analogies of the cultural features of these hypotheses in the respective cultures. More specifically, determining for which cultures all features from the cultural dimensions on the left side of the model match, or inversely which cultures fit the HCI data matches (C) and (G) as shown in [20]. 3) Classifying the cultures corresponding to the antecedence of the rules in the model (left side). 4) Classifying the cultures corresponding to the consequence of the rules in the model (right side). 5) Checking how many cultures on the left side are in accordance with those on the right side (the higher the analogy, the more correct the rules in the model are). By and by, cultures must be analyzed this way on the country level, within countries and within cultures, user groups, essentially at any possible group level, which also includes all indigenous perspectives, finally leaving the concept of cultural classification at all.. The list of cultures confirming the model will increase with time and with it the reliability and the validity of the model. After the model's reliability is judged to be good enough (test end criteria could be a list of sufficiently similar cultures as in step 5 just described), it can be applied to any possible context/domain. At present, within the framework of the test setting, context must be kept constant or minimized completely to control the confirmative process by capturing truly cultural influences.

\subsection{Recommendations and Solutions for IUID}

All engineers developing products for cultures different from their own can use the model to gain first impressions about culturally imprinted differences in HCI regarding information processing and interaction style. The practitioners must reflect on their use cases and reconsider the HCI design based on the output of the model. For example, if the designated cultural user group exhibits high relationship orientation, then information density as well as information and interaction frequency will be high. From this, it can be derived that the user group on average most probably expects applications providing high information flow and interaction activity. The designer can resultantly decide to present more message boxes more frequently to those users than to a user group that is task oriented and expecting fewer disturbances by messages during concentration on the task. One of the most important implications for practitioners in HCI design is that the model can be used to derive first design recommendations for the de- 
sired culture because the model encompasses a standardized set of the characteristics of the designated cultural group determined by cultural models that can be adjusted to every culture. After determining the cultural values of the designated culture using VSM08 from [32], or estimating them by reviewing literature in cultural studies (e.g., [33] and [64]), the results can be input to the model. The output of the model can be directly related to HCI design relevant aspects. For instance, more aspects can be addressed in intercultural HCI design from an HCI designer than simple translations and adding input method editors for user interfaces required in China. This also implicates design recommendations regarding the system architecture: The way in which the computer interacts with the user must be adaptable in such a way that the system can cope with the usage requirements, which depend as much on the cultural imprint and experience of the user as on the current situation. Moreover, the necessary variables must be considered in the design of the system architecture, for example, in the implementation of additional variables (e.g., number of displayed pieces of information or color styles). These results also serve as a basis for the optimization of the methods and processes of intercultural usability engineering and intercultural user interface design because they describe the interaction behavior of users during communication with technical systems depending on the culture of the user.

\section{Conclusion and Outlook}

The IUID method-mix represents a hybrid approach integrating several cultural methods. Based on the method of culture-oriented HCI design (MCD, see [2]), cultural differences are identified based on cultural dimensions and cultural variables are derived for the project. With this knowledge of cultural differences and affected aspects of the HCI system, user interface characteristics (see [28]) and HCI dimensions (see [20]) are used to determine and support further hypothesis-driven effects on HCI design. The cultural influence on the HCI design can be represented by the relationships between the expressions of cultural dimensions and the expressions of the variables relevant for the HCI design [21]. Successful explanatory models can be applied to new examples, use cases or products and thus empirically verified, which in turn allows predictive design recommendations. Even if the investigation and consideration of hidden cultural variables for intercultural HCI design, which relates to culturally shaped interaction and dialogue design based on empirical research, are still ongoing, applying the IUID method-mix is a sensible approach towards systematic intercultural user interface design (IUID) using an explanatory model for culturally influenced HCI. Areas such as intercultural usability engineering and intercultural user interface design can benefit to the extent that the model is further developed and validated because the model is generic enough to be applied to arbitrary cultural groups with arbitrary HCI contexts: Even if the culture (i.e., the orientation system) of the designated group changes, the model need not be 
adapted. Only the new characteristics of the culture of the designated group must be determined anew (cf. adapting to new values of [32] or other such as [33] or [64]) and fed as updated input to the values of the cultural dimensions in the model for culturally-adaptive systems (cf. [25]) without classifying to cultures (cf. the revised principle of CAHMI in [20]). Hence, the ideas presented in this article represent a reasonable step toward a model of culturally influenced HCI. For example, the HCI style of different cultural groups can be compared using the HCI style score, which is computed from the values of cultural dimensions. Using these values, the HCI designer can prognosticate the localization effort and expenditures. However, even if some evidence and rules could be obtained for the core of the model of culturally influenced HCI, the final analysis of the intercultural $\mathrm{HCI}$ design process and its related cultural differences as well as recommendations for intercultural HCI design is still outstanding. Nevertheless, the presented approach constructed on basic physical dimensions has the power to build the foundation of an general model for intercultural HCI design, which incorporates many more aspects than merely the relationship between cultural dimensions and HCI dimensions such as HCI design rules, recommendations, processes, and methods, which are applicable for cultural contexts in HCI in general. Along the trend in research on culture and HCI, the author plans to create a tool presenting the relationship between the cultural and the HCIDs derived from the suggested model and based on the HCI style score. This application can support HCI designers to get an impression of what HCI aspects must be taken into account when designing user interfaces for another culture and what efforts it requires to take cultural context into account depending on the cultural distance between the culture of the HCI designers and the intended end users described by cultural dimensions. Moreover, the focus of investigating cultural differences will shift from the national level to a regional level and even to any other situation to cover all cultural contexts. Methods, models and theories have to be adapted and improved upon in the near future by taking the results from many empirical studies into account to derive and optimize processes for intercultural HCI design and intercultural usability engineering and thereby to establish international norms and to develop tools that finally augment the international standards of research covering arbitrary cultural contexts in HCI.

\section{Acknowledgements}

I thank all persons who supported me since I started work on this topic.

\section{Conflicts of Interest}

The author declares no conflicts of interest regarding the publication of this paper.

\section{References}

[1] Honold, P. (2000) Culture and Context: An Empirical Study for the Development of 
a Framework for the Elicitation of Cultural Influence in Product Usage. International Journal of Human-Computer Interaction, 12, 327-345. https://doi.org/10.1080/10447318.2000.9669062

[2] Röse, K. (2002) Model of Culture and Their Applicability for Designing User Interfaces. Conference WWDU 2002-World Wide Work, Berchtesgaden, 22-25 May 2002, 319-321.

[3] Heimgärtner, R. and Holzinger, A. (2005) Towards Cross-Cultural Adaptive Driver Navigation Systems. In: Holzinger, A. and Weidmann, K.-H., Eds., Empowering Software Quality. How Can Usability Engineering Reach These Goals? 1st Usability Symposium, HCI\&UE Workgroup, Vienna, 53-68.

[4] Nielsen, J. (1990) Designing User Interfaces for International Use. Elsevier, Amsterdam, 230.

[5] Hoft, N.L. (1996) Developing a Cultural Model. In: Del Galdo, E.M. and Nielsen, J., Eds., International Users Interface, John Wiley \& Sons, Inc., Hoboken, NJ, 41-73.

[6] Day, D.L. (1991) The Cross-Cultural Study of Human-Computer Interaction: A Review of Research Methodology, Technology Transfer, and the Diffusion of Innovation. 3 rd National Conference on Librarians and International Development, Corvallis, OR, 30 April 1991, 25 p.

https://eric.ed.gov/?q=The+Cross-Cultural+Study+of + Human-Computer+Interacti on $\% 3 \mathrm{~A}+\mathrm{A}+$ Review + of + Research + Methodology $\% 2 \mathrm{C}+$ Technology + Transfer $\% 2 \mathrm{C}+\mathrm{a}$ nd+the+Diffusion + of + Innovation

[7] Cagiltay, K. (1999) Culture and its Effects on Human-Computer-Interaction. In: Collis, B. and Oliver, R., Eds., Proceedings of World Conference on Educational Multimedia, Hypermedia and Telecommunications 1999, AACE, Chesapeake, VA, 1626.

[8] Jetter, H.-C. (2004) Interkulturelles UI Design und UI Evaluation. Universität Konstanz, Baden-Württemberg, Germany.

[9] Leidner, D.E. and Kayworth, T. (2006) Review: A Review of Culture in Information Systems Research: Toward a Theory of Information Technology Culture Conflict. MIS Quarterly, 30, 357-399. https://doi.org/10.2307/25148735

[10] Vatrapu, R. and Suthers, D. (2007) Culture and Computers: A Review of the Concept of Culture and Implications for Intercultural Collaborative Online Learning. In: Lecture Notes in Computer Science: IWIC07 Proceedings of the 1st International Conference on Intercultural Collaboration, Springer-Verlag, Berlin, Heidelberg, 260-275.

[11] Clemmensen, T. and Roese, K. (2010) An Overview of a Decade of Journal Publications about Culture and Human-Computer Interaction (HCI). In: Katre, D., Orngreen, R., Yammiyavar, P. and Clemmensen, T., Eds., Human Work Interaction Design: Usability in Social, Cultural and Organizational Contexts. IFIP Advances in Information and Communication Technology, Springer, Berlin, Heidelberg. https://doi.org/10.1007/978-3-642-11762-6 9

[12] Heimgärtner, R. (2013) Intercultural User Interface Design. In: Blashki, K. and Isaias, P., Eds., Emerging Research and Trends in Interactivity and the $\mathrm{Hu}$ man-Computer Interface, IGI Global, Hershey, PA. https://doi.org/10.4018/978-1-4666-4623-0.ch001

[13] Pereira, R., et al. (2015) The Value of Values for HCI: An Informed Discussion beyond Philosophy. In: Proceedings of the 14th Brazilian Symposium on Human Factors in Computing Systems, ACM, Salvador, Brazil, 1-10. https://doi.org/10.1145/3148456.3148500 
[14] Zheng, Y.-L., et al. (2018) An Exploratory Study on Design and Implement an Emotional Karaoke Robot (EKR). In: Rau, P.L., Eds., Cross-Cultural Design. Methods, Tools, and Users. Lecture Notes in Computer Science, Springer International Publishing, Cham. https://doi.org/10.1007/978-3-319-92141-9 21

[15] Honold, P. (1999) Cross-Cultural Usability Engineering: Development and State of the Art. In: Proceedings of HCI International (the 8th International Conference on Human-Computer Interaction) on Human-Computer Interaction: Ergonomics and User Interfaces, Lawrence Erlbaum Associates Inc., Mahwah, NJ, 1232-1236.

[16] Heimgärtner, R., et al. (2017) Interkulturelle Erforschung und Gestaltung von Benutzungsschnittstellen (UI) und Benutzererfahrung (UX). In: Burghardt, M., Wimmer, R., Wolff, C. and Womser-Hacker, C., Eds., Mensch und Computer 2017 -Workshopband, Gesellschaft für Informatik, Regensburg.

[17] Abdelnour-Nocera, J., et al. (2011) Re-Framing HCI through Local and Indigenous Perspectives. In: Campos, P., Graham, N., Jorge, J., Nunes, N., Palanque, P. and Winckler, M., Eds., Human-Computer Interaction, Lecture Notes in Computer Science, Springer-Verlag, Berlin, New York.

https://doi.org/10.1007/978-3-642-23768-3 141

[18] Clemmensen, T. (2009) Towards a Theory of Cultural Usability: A Comparison of ADA and CMU Theory. In: Katre, D., Orngreen, R., Yammiyavar, P. and Clemmensen, T., Eds., Human Work Interaction Design: Usability in Social, Cultural and Organizational Contexts. IFIP Advances in Information and Communication Technology, Springer, Berlin, Heidelberg, 98-112. https://doi.org/10.1007/978-3-642-11762-6 9

[19] Clemmensen, T. (2009) A Framework for Thinking about the Maturity of Cultural Usability. In: Blanchard, E.G. and Allard, D., Eds., Handbook of Research on Culturally-Aware Information Technology: Perspectives and Models, Idea Group Publishing, Hershey, PA.

[20] Heimgärtner, R. (2012) Cultural Differences in Human-Computer Interaction. De Gruyter Oldenbourg, Berlin.

[21] Heimgärtner, R. (2013) Reflections on a Model of Culturally Influenced Human Computer Interaction to Cover Cultural Contexts in HCI Design. International Journal of Human-Computer Interaction, 29, 205-219. https://doi.org/10.1080/10447318.2013.765761

[22] Heimgärtner, R. (2014) ISO 9241-210 and Culture?-The Impact of Culture on the Standard Usability Engineering Process. In: Marcus, A., Ed., Design, User Experience, and Usability. User Experience Design Practice. Lecture Notes in Computer Science, Springer, Cham, 39-48. https://doi.org/10.1007/978-3-319-07638-6 5

[23] Heimgärtner, R. (2016) Intercultural User Interface Design. In: Web Design and Development. Concepts, Methodologies, Tools, and Applications, IGI Global, Hershey, PA, 113-146.

[24] Heimgärtner, R. (2017) Using Converging Strategies to Reduce Divergence in Intercultural User Interface Design. Journal of Computer and Communications, 5, 84-115. https://doi.org/10.4236/jcc.2017.54006

[25] Heimgärtner, R. (2018) Culturally-Aware HCI Systems. In: Faucher, C., Ed., Advances in Culturally-Aware Intelligent Systems and in Cross-Cultural Psychological Studies. Intelligent Systems Reference Library, Springer, Cham, 11-37. https://doi.org/10.1007/978-3-319-67024-9 2

[26] Heimgärtner, R. (2019) Interkulturelles User Interface Design. Springer, Berlin, Heidelberg. https://doi.org/10.1007/978-3-030-17427-9 
[27] Honold, P. (2000) Intercultural Usability Engineering: Barriers and Challenges from a German Point of View. In: Day, D.L., del Galdo, E.M. and Prabhu, G.V., Eds., Designing for Global Markets 2, 137-147. 2nd International Workshop on Internationalization of Products and Systems, Baltimore, MD, 13-15 July 2000, 137-147.

[28] Marcus, A. (2001) Cross-Cultural User-Interface Design. In: Smith, M.J.S.G. Ed., Proceedings of Human-Computer Interface Internet, Lawrence Erlbaum Associates, Mahwah, NJ, 502-505.

[29] Heimgärtner, R. (2007) Cultural Differences in Human Computer Interaction: Results from Two Online Surveys. In: Open Innovation, UVK: Ultra Virus Killer, Konstanz.

[30] Heimgärtner, R., Tiede, L.-W. and Windl, H. (2011) Empathy as Key Factor for Successful Intercultural HCI Design. In: Marcus, A., Ed., Design, User Experience, and Usability. Theory, Methods, Tools and Practice. Lecture Notes in Computer Science, Springer, Berlin, Heidelberg. https://doi.org/10.1007/978-3-642-21708-1 62

[31] Thomas, A. (1996) Psychologie interkulturellen Handelns. Hogrefe, Göttingen, Seattle, WA.

[32] Hofstede, G.H., Hofstede, G.J. and Minkov, M. (2010) Cultures and Organizations: Software of the Mind. 3rd Edition, McGraw-Hill, Maidenhead, Berkshire.

[33] Inglehart, R., Moreno, A. and Basanez, M. (1998) Human Values and Beliefs: A Cross-Cultural Sourcebook. University of Michigan Press, ¡Ann Arbor, MI. https://doi.org/10.3998/mpub.14858

[34] Maletzke, G. (1996) Interkulturelle Kommunikation: Zur Interaktion zwischen Menschen verschiedener Kulturen. Westdeutscher Verlag, Opladen, 226.

[35] Hofstede, G. (1984) Culture's Consequences: International Differences in Work-Related Values. Sage, Beverly Hills, CA, 327.

[36] Hodicová, R. (2007) Psychische Distanz und Internationalisierung von KMU: Empirische Untersuchung am Beispiel des Sächsisch-tschechischen Grenzraumes. Deutscher Universitätsverlag, Wiesbaden.

[37] Hofstede, G. (1994) VSM94: Values Survey Module 1994 Manual. IRIC, Tilberg, Netherlands.

[38] Minkov, M. and Hofstede, G. (2012) Is National Culture a Meaningful Concept?: Cultural Values Delineate Homogeneous National Clusters of in-Country Regions. Cross-Cultural Research, 46, 133-159. https://doi.org/10.1177/1069397111427262

[39] Hofstede, G.H. (1991) Cultures and Organizations: Software of the Mind. McGraw-Hill, London, 279.

[40] Hall, E.T. and Hall, M.R. (2009) Understanding Cultural Differences: Germans, French and Americans. Intercultural Press, Boston, MA.

[41] Adler, N.J. and Gundersen, A. (2008) International Dimensions of Organizational Behavior. Thomson South-Western, Mason, OH, 398.

[42] Condon, J.C. (1984) With Respect to the Japanese: A Guide for Americans. Intercultural Press, Yarmouth, 92.

[43] Kluckhohn, F. and Strodtbeck, F.L. (1961) Variations in Value Orientations. Greenwood Press, Westport, CT, 437.

[44] Trompenaars, F. and Hampden-Turner, C. (2012) Riding the Waves of Culture: Understanding Diversity in Business. Nicholas Brealey Publishing, London.

[45] Victor, D.A. (1998) International Business Communication. 7th Edition, Harper Collins, New York, 280. 
[46] Levine, R.V. and Norenzayan, A. (1999) The Pace of Life in 31 Countries. Journal of Cross-Cultural Psychology, 30, 178-205. https://doi.org/10.1177/0022022199030002003

[47] Marcus, A. (2001) International and Intercultural User Interfaces. In: Stephanidis, C., Ed., User Interfaces for All: Concepts, Methods, and Tools, Lawrence Erlbaum, Mahwah, NJ, 47-63. https://doi.org/10.1201/9780429285059-3

[48] Inglehart, R.F. (2008) Changing Values among Western Publics from 1970 to 2006. West European Politics, 31, 130-146. https://doi.org/10.1080/01402380701834747

[49] Röse, K. (2002) Methodik zur Gestaltung interkultureller Mensch-Maschine-Systeme in der Produktionstechnik. University of Kaiserslautern, Kaiserslautern, 244.

[50] Honold, P. (1999) “Cross-Cultural” or "Intercultural”-Some Findings on International Usability Testing. In: Prabhu, G.V. and Del Galdo, E.M., Eds., Designing for Global Markets 1, First International Workshop on Internationalization of Products and Systems, Backhouse Press, Rochester, New York, 107-122.

[51] Heimgärtner, R. (2008) A Tool for Getting Cultural Differences in HCI. In: Human Computer Interaction: New Developments, IntechOpen Limited, London, 343-365. https://doi.org/10.5772/5870

[52] Röse, K., Liu, L. and Zühlke, D. (2001) Design Issues in Mainland China: Demands for a Localized Human-Machine-Interaction Design. In: Smith, M.J. and Salvendy, G., Eds., Systems, Social, and Internationalization Design Aspects of $\mathrm{Hu}$ man-Computer Interaction: Volume 2, Lawrence Erlbaum Associates, London, 532-536.

[53] Röse, K. (2002) Kulturmodelle und ihre Anwendbarkeit beim User Interface Design. 305-317.

[54] Schlögl, C. (2005) Information and Knowledge Management: Dimensions and Approaches. Information Research, 10, 10-14.

[55] Heimgärtner, R. (2005) Research in Progress: Towards Cross-Cultural Adaptive Human-Machine-Interaction in Automotive Navigation Systems. In: Day, D. and del Galdo, E.M., Eds., Proceedings of the Seventh International Workshop on Internationalization of Products and Systems, Grafisch Centrum Amsterdam, Amsterdam, The Netherlands, 97-111.

[56] Bernsen, N.O., Dybkjær, H. and Dybkjær, L. (1998) Designing Interactive SpeechSystems. 2nd Print Edition, Springer, London.

[57] Hall, E.T. (1959) The Silent Language. Doubleday, New York.

[58] Preim, B. and Dachselt, R. (2010) Interaktive Systeme-Band I: Grundlagen, Graphical User Interfaces, Informationsvisualisierung. Springer Verlag, Berlin, Heidelberg.

[59] Vollhardt, J.K., Migacheva, K. and Tropp, L.R. (2008) Social Cohesion and Tolerance for Group Differences. In: de Rivera, J., Ed., Handbook on Building Cultures of Peace, Peace Psychology Book Series, Springer, New York, 139-152. https://doi.org/10.1007/978-0-387-09575-2_10

[60] Nelius, M. (2003) Mousemap-basierte Erkennung der Problemfelder von Anwendern bei der Bedienung von Software. Department of Computer Science, University of Rostock, Rostock, Germany.

[61] Dix, A., Finlay, J. and Abowd, G.D. (2011) Human-Computer Interaction. Pearson, London.

[62] Marcus, A. (2006) Cross-Cultural User-Experience Design. In: Barker-Plummer, D., Cox, R. and Swoboda, N., Eds., Diagrammatic Representation and Inference, 
Springer, Berlin, Heidelberg, 16-24. https://doi.org/10.1007/11783183 4

[63] Nielsen, J. (2001) Usability Metrics. https://www.nngroup.com/articles/usability-metrics/

[64] Schwartz, S.H. (2004) Mapping and Interpreting Cultural Differences around the World. In: Vinken, H., Soeters, J. and Ester, P., Eds., Comparing Cultures, Dimensions of Culture in a Comparative Perspective, Leiden, Brill, The Netherlands, 43-73.

[65] Lewis, R.D. (2000) Handbuch internationale Kompetenz: Mehr Erfolg durch den richtigen Umgang mit Geschäftspartner weltweit. Campus Verlag, Frankfurt/Main, 473.

[66] Gould, E.W., Marcus, A. and Chavan, A.L. (2006) International Usability Evaluation SIG: Issues and Strategies. In: $C H I$ '06 Extended Abstracts on Human Factors in Computing Systems, ACM, New York, 399-401. https://doi.org/10.1145/1125451.1125537

[67] Galtung, J. (1981) Structure, Culture, and Intellectual Style: An Essay Comparing Saxonic, Teutonic, Gallic and Nipponic Approaches. Social Science Information, 20, 817.

[68] Hall, E.T. (1976) Beyond Culture. Anchor Books, New York.

[69] Röse, K., Zühlke, D. and Liu, L. (2001) Similarities and Dissimilarities of German and Chinese Users. In: Johannsen, G., Ed., 8th IFACIIFIP/IFORS/IEA Symposium on Analysis, Design, and Evaluation of Human-Machine Systems, Germany, Kassel, 24-29.

[70] Rathje, S. (2003) Ist wenig kulturelles Verständnis besser als gar keins?-Problematik der Verwendung von Dimensionsmodellen zur Kulturbeschreibung. https://www.interculture-online.info

[71] Nielsen, J., Vatrapu, R. and Bødker, M. (2010) Culture and (I)literacy as Challenges to Scandinavian Cooperative Design. CiteSeer ${ }^{X}, 271-274$. 